\title{
Phytochemical Analysis of Bioactive Extracts and Seed Oil of Three Euphorbia Species from Algerian Flora by LC-MS and GC-MS
}

\author{
Nadia Toudert ${ }^{1}$, Farida Zakkad ${ }^{2}$, Noureddine Dadda ${ }^{2}$, Abdelouaheb Djilani ${ }^{2}$, \\ Amadou Dicko ${ }^{3}$, and Salah Eddine Djilani ${ }^{\star}$ \\ ${ }^{1}$ Laboratory of Physical Chemistry of Materials, El Chadli Ben Djedid University, El Tarf, Algeria \\ ${ }^{2}$ Laboratory of Synthesis and Organic Biocatalysis, Badji Mokhtar University, Annaba, Algeria \\ ${ }^{3}$ Université de Lorraine, UR-AFPA (Unité de Recherche Animal et Fonctionnalité des Produits Animaux), France
}

\section{*Corresponding author:}

tel: $+213-552549827$

email: djilanisalah2000@yahoo.fr

Received: August 11, 2020

Accepted: March 6, 2021

DOI: $10.22146 /$ ijc.56679

\begin{abstract}
Euphorbia species possess pharmacological properties that have been widely used for medical purposes worldwide. In this paper, three plants belonging to the Euphorbia genus growing in North-East of Algeria were studied. The phenolic contents were identified using LC-MS, while the fatty acid composition of their fixed oils was determined with GC-MS. The quantification of the total condensed tannins and the leaves' entire anthocyanin content were performed using photometric methods. The main constituents of the polyphenolic compounds identified by LC-MS were ascorbic, chlorogenic, and ellagic acids. The oil yield of the seeds of E. terracina, E. biumbellata, and $\mathrm{E}$. dendroides was $17.48 \%, 18.5 \%$, and $20.05 \%$, respectively. Quantitative analyses of these oils using GC-MS showed variations in the species' fatty acid constituents' concentrations and compositions. Besides, the phytochemical screening results showed that E. terracina possessed a high amount of tannin and anthocyanin content compared with other studied plants.
\end{abstract}

Keywords: Euphorbia; polyphenols; oil; LC-MS; CG-MS

\section{- INTRODUCTION}

More attention has been given to plants as a human medicaments source, especially in some developing countries, as plant-derived medicines have made significant contributions to human health and wellbeing [1-3]. Among the natural products found in plants, polyphenols constitute one of the largest classes of the plant's secondary metabolite, which has an important role in preventing and restricting free radicals.

The plant Euphorbia belongs to the family Euphorbiaceae that is widespread worldwide and widely present in the tropical region. It is a large family of flowering plants, including 300 genera and over 5000 species [4-5].

The Euphorbia species are considered critical medicinal plants used mainly in folk medicine all over the world. In Africa, Euphorbia species were used to treat various diseases such as skin disease, migraines, gonorrhea, fungal and inflammatory disorders, .and sexual transmission [6-7]. In Nepal, the latex of E. milii is used to cure sprains [8], while in China, it is used to cure hepatitis [9]. In Pakistan E. hellioscopia leaves are used to relieve constipation [10]. In India, E. neriifolia is known for its medicinal value, such as antibacterial, antifungal, antiviral, and antioxidant [11]. In Nigeria, essential oils from the leaves of E. milii are used for insecticidal action [12].

Few previous works are reported on the use of E. biumbellata, E. terracina, and E. dendroides in folk medicine. According to ethnobotanical investigations, it was observed that E. terracina leaves have been used as a remedy for paralysis and fever [13]. And E. dendroides was used as a fish poison and as a cathartic, while E. biumbellata latex has been used to cure warts [4].

Phytochemical studies of Euphorbia dendroides exhibited the presence of polyphenols, flavonoids, and 
jatrophane esters [4], while in previous research studies, Euphorbia terracina was found to contain a variety of bioactive chemical compounds such as saponins, tannins [13], triterpenes, flavenoids and coumarins [14].

This research aims to identify the chemical constituents contained in the seeds and leaves of the three Algerian plants: E. biumbellata, E. dendroides, and E. terracina, with LC-MS. An additional goal is to determine the fatty acid composition of oil obtained from their seeds using GC-MS analysis.

\section{- EXPERIMENTAL SECTION}

\section{Materials}

E. biumbellata, E. dendroides, and E. terracina were collected from El Kala National Park in the northeast of Algeria in March 2019. The identification was carried out by the botanists of the Biology Department, Badji Mokhtar University. ph005_48, ph005_49, ph006_04, voucher specimens of E. biumbellata, E. dendroides, and $E$. terracina, respectively, were deposited in the Herbarium of Gérard De Belair.

The plants were cleaned and air-dried in the shade at room temperature for three weeks. The dry seeds and sheets were ground at the mill until they obtain fine homogeneous powders and stored in dark glass flasks to protect them from humidity and light till theirs use in further analysis.

\section{Instrumentation}

The main apparatus used in the research were rotary evaporator (Buchi R-124), analytical balance, Shimadzu Spectrophotometer UV-1800, gas chromatography-mass spectrometer (GC-MS) (Shimadzu QP-2010S), liquid chromatography-mass spectrometry (Shimadzu LCMS2020S).

\section{Procedure}

\section{Extract preparation}

The weighed amount of each part (sheets and seeds) of the samples was extracted in a known volume of the solvent $\mathrm{MeOH}-\mathrm{H}_{2} \mathrm{O}(70 / 30$ : v/v) for $24 \mathrm{~h}$ with intermittent shaking. Each extracted material is filtered through Whatman filter paper No.1 and centrifuged at $4000 \mathrm{rpm}$ for $15 \mathrm{~min}$. The supernatant is then stored at
$-4{ }^{\circ} \mathrm{C}$ for further use in the phytochemical analysis, total anthocyanin contents, determination of antioxidant activity, and LC-MS analysis.

\section{Analysis of chemical composition}

Total condensed tannin contents (TCT). The tannin contents were estimated with the vanillin- $\mathrm{HCl}$ method [15] with slight modification, using catechin as a reference compound. In brief, $1 \mathrm{~g}$ of dry residue was added to $15 \mathrm{~mL}$ of $\mathrm{MeOH}-\mathrm{HCl}(1 \%)$ in a test tube. The tube was placed in a water bath at $35{ }^{\circ} \mathrm{C}$ for $30 \mathrm{~min}$, centrifuged at $1532 \times \mathrm{g}$, and finally filtered. Aliquots $(0.5 \mathrm{~mL})$ of extract were mixed with $3 \mathrm{~mL}$ of vanillin$\mathrm{HCl}$ reagent (4\% in methanol) in test tubes. After $20 \mathrm{~min}$ of incubation at room temperature, the absorbance was read at $500 \mathrm{~nm}$, using a UV-visible spectrophotometer. The estimation of condensed tannins was carried out in triplicate, and the results were expressed as mg catechin equivalent/g of dry matter.

Total anthocyanin compounds (TAC). The samples' total anthocyanins compounds were determined using a Vis- spectrophotometer according to the $\mathrm{pH}$-differential method [16]. Two buffer systems, potassium chloride buffer, $\mathrm{pH} 1.0(0.025 \mathrm{M})$, and sodium acetate buffer, $\mathrm{pH}$ $4.5(0.4 \mathrm{M})$, were used. Absorbance was measured at 520 and $700 \mathrm{~nm}$. TAC Results were expressed as cyanidin-3glucoside equivalents and calculated using the formula:

$\mathrm{TA}(\mathrm{mg} / \mathrm{g})=\frac{\Delta \mathrm{A} \times \mathrm{MW} \times \mathrm{DF} \times 1000}{\varepsilon \times 1}$

where $\triangle \mathrm{A}$ : difference of absorbance; $\mathrm{DF}=$ dilution factor; $\mathrm{MW}$ (molecular weight) $=449.2 \mathrm{~g} / \mathrm{mol} ; 1=$ cuvette pathlength in $\mathrm{cm} ; \varepsilon=26,900 \mathrm{~L} / \mathrm{mol} . \mathrm{cm}$.

Evaluation of total antioxidant capacity by phosphomolybdate (PPM) method. The total antioxidant capacity assay of plant extract was carried out by the phosphomolybdenum method [17-18]. A $0.1 \mathrm{~mL}$ of sample solution was mixed with $1 \mathrm{~mL}$ of reagent solution $(0.6 \mathrm{M}$ sulfuric acid, $28 \mathrm{mM}$ sodium phosphate, and $4 \mathrm{mM}$ ammonium molybdate). Against a blank containing $0.1 \mathrm{~mL}$ of methanol mixed with $1 \mathrm{~mL}$ of reagent solution. The test tube contained the reaction mixture was covered with aluminum foil and incubated at $95^{\circ} \mathrm{C}$ for $90 \mathrm{~min}$. After the samples were cooled to room temperature, the absorbance was measured at $695 \mathrm{~nm}$. 
Ascorbic acid was used as a standard. The antioxidant capacity was estimated using the following formula:

Tot. antioxidant cap. $(\%)=\frac{\text { Abs. of control }- \text { Abs. of sample }}{\text { Abs. of control }} \times 100$

Total antioxidant activity was expressed as $\mathrm{mg}$ vitamin $\mathrm{C}$ equivalent/1g dry weight, and the values are presented as the means of triplicate analysis.

\section{Fixed oil analysis}

Oil extraction. Seeds powder of different plants $E$. biumbellata, E. dendroides, and E. terracina was extracted by Soxhlet method with hexane solvent for $8 \mathrm{~h}$. After solvent evaporation under reduced pressure, the oil was recovered and stored in glass vials at $4{ }^{\circ} \mathrm{C}$ for further analysis.

Chemical characteristics of oil. Oil characteristics, namely saponification number (SP), iodine value (IV), and acidity, were determined according to AOCS standard methods [19].

\section{GC-MS analysis}

The fatty acid composition is determined as the methyl esters of fatty acids by gas-liquid chromatography. Methyl esters of the fatty acids (FAME) of the three seed oils were prepared according to a convenient method [20], using $\mathrm{BF}_{3}$-methanol at $60^{\circ} \mathrm{C}$.

The FAME was recovered using $n$-hexane, and an aliquot $(2 \mu \mathrm{L})$ was injected automatically in splitless mode into the GC-MS apparatus. The carrier gas was helium, the temperatures of the injector and detector were held at $300{ }^{\circ} \mathrm{C}$. Electron impact ionization was achieved with ionization energy IE of $70 \mathrm{eV}$. The identification of the components was based on the comparison of their mass spectra with those of the NIST 11 mass spectral library.

\section{LC-MS analysis}

The concentration of standards solution was $1 \mathrm{mg}$ in $1 \mathrm{~mL}$ of methanol-water (1:1) solution. Measurements were carried out at $280 \mathrm{~nm}$ wavelength. Standards and extracts were filtered through a Millipore membrane $(0.45 \mu \mathrm{m})$. LC-MS method was used for the determination of bioactive ingredient content in our plant's hydro-methanolic extracts.

An aliquot of extract $(20 \mu \mathrm{L})$ was injected onto a Gemin C-18 column $(4.6 \mathrm{~mm}$ i.d. $\times 150 \mathrm{~mm})$. The solvents used were formic acid-acidified water at $0.5 \%$ (A) and acetonitrile (B). The elution gradient was $35 \mathrm{~min}$ with a flow rate of $0.6 \mathrm{~mL} / \mathrm{min}$ (Table 1). Spectra were recorded in negative ionization mode in full scan between 0 and $1000 \mathrm{Da}$.

\section{- RESULTS AND DISCUSSION}

\section{Chemical Composition}

Previous phytochemical screening of the phytochemical constituents of various extracts from the three plants [21] showed that they are very rich in polyphenols, lipids, tannins, flavonoids, fats and oils, anthocyanins, sterols, and terpenes. In contrast, alkaloids and starch were not detected, and E. dendroides extract gave a negative result for cardenolides.

\section{TAC, TTC, and phosphomolybdate assay}

The results of TAC, TTC, and PPM tests of leave extracts are shown in Table 2 . The quantitative estimation of chemical constituents revealed that $E$. terracina leaves contained the highest tannins and anthocyanin levels with $15.54 \mathrm{mg}$ catechin/g and $1.070 \mathrm{cy}-3$-gly/g, respectively,

Table 1. Gradient elution

\begin{tabular}{lc}
\hline Instants (min) & $\mathrm{A} \%: \mathrm{B} \%$ \\
\hline $0-22.50$ & $90: 10$ to $50: 50$ \\
$22.50-23$ & $50: 50$ to $10: 90$ \\
$23-29$ & $10: 90$ \\
$29-29.50$ & $10: 90$ to $90: 10$ \\
$29.50-35$ & $90: 10$ \\
\hline
\end{tabular}

Table 2. Values of total anthocyanins content (TAC), total tannins content (TTC), and total antioxidant capacity (phosphomolybdate assay) of different leaves extracts

\begin{tabular}{lccc}
\hline TEST & E. biumbellata & E. dendroides & E. terracina \\
\hline TTC $(\mathrm{CE} \mathrm{mg/g} \mathrm{Dm)}$ & $6.41 \pm 0.13$ & $7.31 \pm 0.33$ & $15.54 \pm 0.56$ \\
TAC (AC mg/g Dm) & $0.23 \pm 0.42$ & $0.35 \pm 0.32$ & $1.070 \pm 0.98$ \\
PPM (VCE mg/g Dm) & $9.05 \pm 0.02$ & $8.17 \pm 0.03$ & $8.75 \pm 0.07$ \\
\hline Dm: dry matter & & &
\end{tabular}


exceeding the contents of E. dendroides and E. bumbellata. It was reported that these phytochemical compounds (tannins and anthocyanin) are known to provide support for the bioactive properties of plants [22-23].

The results obtained from the phosphomolybdic acid assay of the three Euphorbia leaves extracts show that all the tested extracts possessed a scavenging activity (Table 2). E. biumbelatta sheets extract exhibited a higher activity than the other two extracts, while $E$. dendroides extract was the least active.

\section{Fixed Oil Analysis}

The yields of oils extracted from E. terracina, E. biumbellata, and E. dendroides were $17.48 \%, 18.5 \%$, and $20.05 \%$, respectively.

\section{Chemical characteristics of the oils}

Results of the chemical characteristics of the three samples are displayed in Table 3. The data indicate considerable variations in acid values, saponification values, and iodine values between the three seed oils.

The acid index is a parameter that demonstrates the quality of the oil. However, the acid value of the oil must not be too high; an acid value of 0.00 to $3.00 \mathrm{mg} \mathrm{KOH} / \mathrm{g}$ oil is recommended for oil to find application in cooking [24]. All the vegetable oils understudy with a high acid value of 5.83 to $10.99 \mathrm{mg} \mathrm{KOH} / \mathrm{g}$, this denotes a high content of free fatty acids, which causes the oil to turn sour and a less storage quality [25].

Iodine value is a measure of the degree of unsaturation. It is used to quantify the number of double bonds present in the oil. Among the different oils analyzed, E. dendroides seed oil displayed the highest iodine value, which reflected a high concentration of unsaturated fatty acids in the oil. On the other hand, $E$. biumbelatta seeds oil showed a low degree of unsaturated fatty acid, which indicated that the oil could be used as a nondrying oil, which helps manufacture soap [26].

The saponification value is inversely compared to the molecular weight of the oil. It helps assess the chain lengths of fatty acids in the oil. All of the analyzed oils showed a high SP number, but E. biumbelatta recorded the highest value.

\section{GC-MS Reports}

The GC-MS analysis of seed oils from the three Euphorbia species allowed us to identify numerous compounds belonging to different chemical families. The active compounds with their molecular mass, retention time, and concentration are presented in Table4.

Table 3. Chemical properties of the seeds oil

\begin{tabular}{lccc}
\hline Chemical characteristics & E. biumbellata & E. dendroides & E. terracina \\
\hline Acid value: $\mathbf{A V ~}(\mathrm{mg} \mathrm{KOH} / \mathrm{g})$ & 5.83 & 10.09 & 10.99 \\
Iodine value: $\mathbf{I V ~}\left(\mathrm{gI}_{2} / 100 \mathrm{~g}\right)$ & 47.58 & 90.41 & 63.45 \\
Saponification: $\mathbf{S P}(\mathrm{mg} \mathrm{KOH} / \mathrm{g})$ & 266.47 & 210.30 & 162.32 \\
\hline
\end{tabular}

Table 4. Principal compounds in oils from seeds

\begin{tabular}{lccccc}
\hline \multicolumn{1}{c}{ Compounds } & $\begin{array}{c}\text { Molar mass } \\
(\mathrm{g} / \mathrm{mol})\end{array}$ & $\begin{array}{c}\text { Retention } \\
\text { time }(\mathrm{min})\end{array}$ & $\begin{array}{c}\text { Euphorbia } \\
\text { biumbelatta }\end{array}$ & $\begin{array}{c}\text { Euphorbia } \\
\text { dendroides }\end{array}$ & $\begin{array}{c}\text { Euphorbia } \\
\text { terracina }\end{array}$ \\
\cline { 4 - 6 } & 270 & 19.35 & $2.08 \pm 0.2$ & $10.05 \pm 0.7$ & $8.5 \pm 1.2$ \\
\hline Hexadecanoic acid, methyl ester & 294 & 21.22 & $14.6 \pm 2.7$ & - & - \\
8,11 -Octadeca-dienoic acid, methyl ester & 320 & 21.64 & $11.3 \pm 1.7$ & - & $13.55 \pm 0.3$ \\
$11,14,17-$-Eicosatrienoic acid, methyl ester & 294 & 21.19 & - & $37 \pm 1.2$ & $31.05 \pm 1.2$ \\
Linoleic acid, methyl ester & 292 & 21.27 & - & $2.3 \pm 0.9$ & - \\
Linolenic acid, methyl ester & 298 & 21.47 & - & $14.35 \pm 0.5$ & - \\
Stearic acid, methyl ester & 652 & 19.92 & - & - & $3.95 \pm 0.2$ \\
Ascorbic acid, dipalmitate & & &
\end{tabular}


The GC-MS chromatogram of the compounds detected is shown in Fig. 1. Results showed that hexadecanoic acid and linoleic acid are present in the various oils. The predominant unsaturated fatty acid is linoleic acid (37\% in E. dendroides, 31.05\% in E. terracina, and $14.06 \%$ in E. buimbelatta). Besides, only E. terracina oil contains a rare and important compound of 1-(+)ascorbic acid 2,6-dihexadecanoate (Fig. 1). Ascorbic acid, dipalmitate has been reported to have many biological properties such as antioxidant, anti-inflammatory, and anti-nociceptive properties [27-28].

\section{LC-MS Analysis}

Different peaks at different retention times were obtained through LC-MS analysis in all three samples, and ten phenolic compounds were identified, and the chromatographic profile of standards and their retention times are represented by Fig. 2 and Table 5 .

The standards retention time values are grouped in Table 5. The results of the chromatographic analysis of the

Table 5. Standards retention time

\begin{tabular}{lc}
\hline Standard & Retention time (min) \\
\hline Ascorbic acid & 3.00 \\
Gallic acid & 4.70 \\
Chlorogenic acid & 8.70 \\
Syringic acid & 10.55 \\
Rutin & 12.53 \\
Ellagic acid & 13.35 \\
Ferulic acid & 13.85 \\
Colchecin & 17.30 \\
Quercitin & 19.90 \\
Cinnamic acid & 20.70 \\
\hline
\end{tabular}

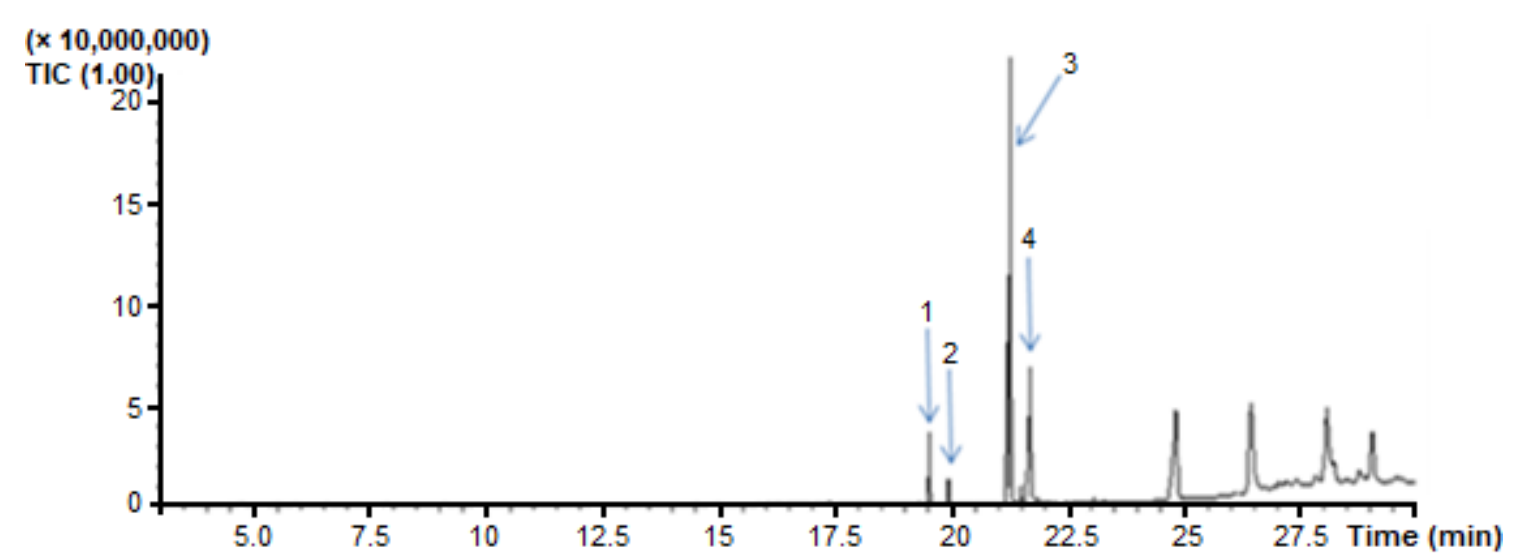

Fig 1. Chromatographic profiles of seeds oil of Euphorbia terracina

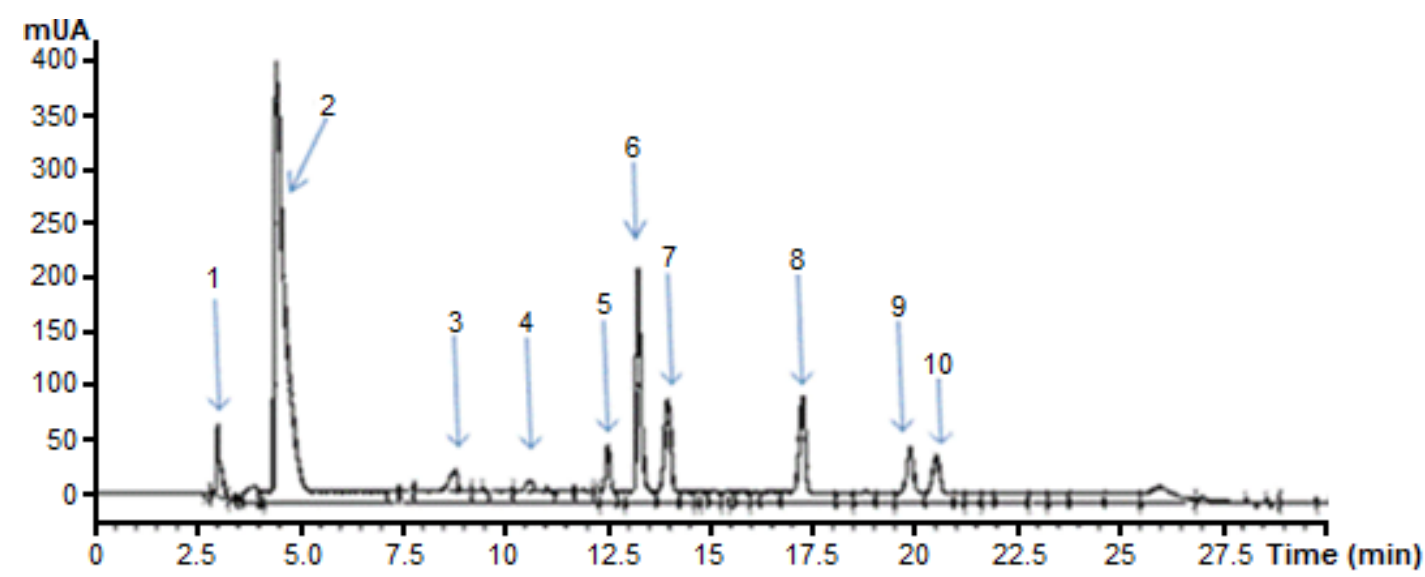

Fig 2. Chromatographic profiles of standards at $280 \mathrm{~nm}$ at $1 \mathrm{mg} / \mathrm{mL}$ : 1: ascorbic acid; 2: gallic acid; 3: chlorogénic acid; 4: syringic acid; 5: rutin; 6: ellagic acid; 7: ferulic acid; 8: colchicin; 9: quercitin; 10: cinnamic acid 
Table 6. Important compounds identified by LC-MS

\begin{tabular}{|c|c|c|c|c|c|c|}
\hline \multirow{2}{*}{ Standards } & \multicolumn{2}{|c|}{ Euphorbia biumbelatta } & \multicolumn{2}{|c|}{ Euphorbia dendroides } & \multicolumn{2}{|c|}{ Euphorbia terracina } \\
\hline & Leaves & Seeds & Leaves & Seeds & Leaves & Seeds \\
\hline Ascorbic acid & + & + & + & + & + & + \\
\hline Gallic acid & + & + & - & + & - & + \\
\hline Chlorogénicacid & + & + & + & + & + & + \\
\hline Syringic acid & - & + & + & + & + & - \\
\hline Rutin & + & + & - & - & + & + \\
\hline Ellagic acid & + & + & + & + & + & + \\
\hline Ferulic acid & + & + & + & + & + & - \\
\hline Colchicin & + & + & - & - & + & - \\
\hline Quercitin & + & + & - & - & - & - \\
\hline Cinnamic acid & - & - & - & - & - & - \\
\hline
\end{tabular}

different leaves and seeds extracts are compiled in Table 6. The compound's chemical structures are elucidated from the standard reference graphs, using the molecular weight data.

From the standard reference graphs, the compounds are elucidated using the molecular weight. The results showed the presence of ascorbic acids, chlorogenic acids, and ellagic acids in the different extracts. The species that contains the more standards are Euphorbia biumbelatta.

Most of the phytoconstituents identified are very important in medicine. They exhibit various pharmacological activities such as antioxidant, antidiabetic, anti-inflammatory, and anticancer [29-30].

\section{- CONCLUSION}

The present work has demonstrated the potential of Euphorbia species growing in Algeria as an important source of secondary metabolites.

Hydro-alcoholic extracts from sheets of the three plants were subjected to quantitative estimation of chemical constituents and antioxidant activity essay. Results showed that total tannin and anthocyanin contents were higher in Euphorbia terracina extract, compared to the two other generates. Whereas, the total antioxidant activity was higher in Euphorbia buimbelatta extract, and was found to be equal in Euphorbia dendroides and Euphorbia terracina extract. In addition, chemical compositions of hydro-methanolic extracts of leaves were analyzed by the LC-MS technique, which leads to the identification of ten compounds with considerable concentrations.

On the other hand, fixed oils of seeds were obtained with the Soxhlet method and analyzed by GCMS apparatus. Linoleic acid was detected as the main FAME among the identified FAMEs in the various oils. From LC-MS and GC-MS results, an appreciable abundance of secondary metabolites in the studied plants was noticed. These results demonstrated the importance of Euphorbia genre as a promising source of new bioactive compounds.

\section{- ACKNOWLEDGMENTS}

The authors would like to thank Pr. Amado DIKOU for his assistant in carrying out the GC-MS and LC-MS analysis. We are also grateful to the anonymous reviewers for their constructive comments on this Manuscript.

\section{- REFERENCES}

[1] Bagewadi, Z.K., Siddanagouda, R.S., and Baligar, P.G., 2014, Phytoconstituents investigation by LCMS and evaluation of antimicrobial and antipyretic properties of Cynodon dactylon, Int. J. Pharm. Sci. Res., 5(7), 2874-2889.

[2] Savithramma, N., Rao, M.L., and Ankanna, S., 2012, Preliminary Phytochemical Screening of Some Important Medicinal Plants, Int. J. Ayurveda Res., 2 (1), 139-145. 
[3] Azmathullah, N.M., Sheriff, M.A., and Mohideen, A.K.S., 2011, Phytochemical screening of Calotropis procera flower extracts and their bio-control potential on Culex sp. mosquito larvae and pupae, Int. J. Pharm. Biol. Arch., 2 (6), 1718-1721.

[4] Ghout, A., Zellagui, A., Gherraf, N., Demirtas, I., Sahin, Y.A., Boukhenaf, M., Lahouel, M., Nieto, G., and Akkal, S., 2018, Antiproliferative and antioxidant activities of two extracts of the plant species Euphorbia dendroides L., Medicines, 5 (2), 36.

[5] Saleem, U., Hussain, K., Ahmad, M., Bukhari, N.I., Malik, A., and Ahmad, B., 2014, Report: Physicochemical and phytochemical analysis of Euphorbia helioscopia (L.), Pak. J. Pharm. Sci., 27 (3), 577-585.

[6] Titilope, K.K., Rashidat, E.A., Christiana, O.C., Kehinde, E.R., Omobolaji, J.N., and Olajide, A.J., 2012, In-vitro antimicrobial activities of Euphorbia hirta against some clinical Isolates, Agric. Biol. J. North Am., 3 (4), 169-174.

[7] Özbilgin, S., and Saltan Citoğlu, G., 2012, Uses of some Euphorbia species in traditional medicine in Turkey and their biological activities, Turk. J. Pharm. Sci., 9 (2), 241-256.

[8] Qaisar, M., Gilani, S.N., Farooq, S., Rauf, A., Naz, R., Shaista, and Pervees, S., 2012, Preliminary comparative phytochemical screening of Euphorbia species, Am.-Eurasian J. Agric. Environ. Sci., 12 (8), 1056-1060.

[9] Sun, Y.X., and Liu, J.C., 2011, Chemical constituents and biological activities of Euphorbia fischeriana Steud, Chem. Biodivers., 8 (7), 1205-1214.

[10] Badshah, L., and Hussain, F., 2011, People preferences and use of local medicinal flora in District Tank Pakistan, J. Med. Plants Res., 5 (1), 2229.

[11] Sharma, V., Janmeda, P., and Singh, L., 2011, A review on Euphorbia neriifolia (Sehund), Spatula DD, 1 (2), 107-111.

[12] Okonkwo, C.O., and Ohaeri, O.C., 2018, Essential oils from the leaves of Euphorbia Mili exert insecticidal activity through disruption in ionic composition, IOSR J. Pharm. Biol. Sci., 13 (4), 46-53.
[13] Jannet, S.B., Hymery, N., Bourgou, S., Jdey, A., Lachaal, M., Magné, C., and Ksouri, R., 2017, Antioxidant and selective anticancer activities of two Euphorbia species in human acute myeloid leukemia, Biomed. Pharmacother., 90, 375-385.

[14] El-Amier, Y.A., Al-Hadithy, O.N., Abdulhadi, H.L., and Fayed, E.M., 2016, Evaluation of antioxidant and antimicrobial activities of Euphorbia terracina L. from deltaic mediterranean coast, Egypt, J. Nat. Prod. Resour., 2 (2), 83-85.

[15] Wafa, G., Amadou, D., Larbi, K.M., and Héla, E.F.O., 2014, Larvicidal activity, phytochemical composition, and antioxidant properties of different parts of five populations of Ricinus communis L., Ind. Crops Prod., 56, 43-51.

[16] Sutharut, J., and Sudarat, J., 2012, Total anthocyanin content and antioxidant activity of germinated colored rice, Int. Food Res. J., 19 (1), 215-221.

[17] Ahmed, D., Khan, M.M., and Saeed, R., 2015, Comparative analysis of phenolics, flavonoids, and antioxidant and antibacterial potential of methanolic, hexanic and aqueous extracts from Adiantum caudatum leaves, Antioxidants, 4 (2), 394-409.

[18] Jan, S., Khan, M.R., Rashid, U., and Bokhari, J., 2013, Assessment of antioxidant potential, total phenolics and flavonoids of different solvent fractions of Monotheca buxifolia fruit, Osong Public Health Res. Perspect., 4 (5), 246-254.

[19] Cunniff, P., 1995, Official Methods of Analysis, $16^{\text {th }}$ Ed., Association of Official Analytical Chemists, Washington DC, US.

[20] Raharjo, T.J., Nurliana, L., and Mastjeh, S., 2011, Phospholipids from pumpkin (Cucurbita moschata (Duch.) Poir) seed kernel oil and their fatty acid composition, Indones. J. Chem., 11 (1), 48-52.

[21] Zeghad, F., Djilani, S.E., Djilani, A., and Dikou, A., 2016, Antimicrobial and antioxidant activities of three Euphorbia species, Turk. J. Pharm. Sci., 13 (1), 47-56.

[22] Elhassan, G.O.M., Adhikari, A., Abdalla, O.M., Shukrulla, A., Khalid, A., Choudhary, M.I., Mesaik, 
M.A., and Yagi, S., 2015, Chemical constituents of Euphorbia polyacantha Boiss. and their immunomodulatory properties, Rec. Nat. Prod., 9 (1), 146-152.

[23] Vijayabaskar, P., and Shiyamala, V., 2012, Antioxidant properties of seaweed polyphenol from Turbinaria ornate (Turner) J. Agardh, 1848, Asian Pac. J. Trop. Biomed., 2 (1), S90-S98.

[24] Agboola, J.B., Abubakre, O.K., Mudiare, E., Adeyemi, M.B., and Hassan, S.B., 2015, Physicochemical characteristics and fatty acids composition of some selected Nigerian vegetable oils for quenching medium, Br. J. Appl. Sci. Technol., 8 (3), 246-253.

[25] Youssef, M.K.E., Eshak, N.S., and Hana, R.S., 2013, Physicochemical characteristics, nutrient content and fatty acid composition of Nigella sativa oil and sesame oil, Food Public Health, 3 (6), 309-314.

[26] Bello, M.O., Akindele, T.L., Adeoye, D.O., and Oladimejir, A.O., 2011, Physicochemical properties and fatty acids profile of seed oil of Telfairia occidentalis Hook F., Int. J. Basic Appl. Sci., 11 (06), 9-14.

[27] Kumar, P.P., Kumaravel, S., and Lalitha, C., 2010, Screening of antioxidant activity, total phenolics and GC-MS study of Vitex negundo, Afr. J. Biochem. Res., 4 (7), 191-195.

[28] Okwu, D.E., and Ighodaro, B.U., 2010, GC-MS evaluation of bioactive compounds and antibacterial activity of the oil fraction from the leaves of Alstonia boonei De Wild, Der Pharma Chem., 2 (1), 261-272.

[29] Vankar, P.S., and Srivastava, J., 2010, Evaluation of anthocyanin content in red and blue flowers, Int. J. Food Eng., 6 (4), 7.

[30] Mohamed, A.H.H., Hegazy, M.E.F., Moustafa, M.F.M., El-Sayed, M.A., Abdel-Farid, I.B., Esmail, A.M., Abdelrazik, M.H., Mohamed, N.S., Nenaah, G., Mohamed, T.A., Shahat, A.A., Karchesy, J., Matsuda, H., and Pare, P.W., 2012, Euphorbia helioscopia: Chemical constituents and biological activities, Int. J. Phytopharmacol., 3 (1), 78-90. 